\title{
The Study on Inventory Problem Based on System Dynamics
}

\author{
Wei Liu ${ }^{1, a,{ }^{*}, Z i x i a n ~ L v}{ }^{2, b}$ \\ ${ }^{1}$ Xiamen university of Tan Kah Kee college, Zhangzhou,China \\ 2 Xiamen university of Tan Kah Kee college, Zhangzhou,China \\ aliuwei568@xujc.com, bSCL13048@stu.xujc.com \\ ${ }^{*}$ Corresponding author
}

Keywords: Manufacturing enterprise, Inventory management, System dynamics, Simulation Abstract. Based on the analysis of the characteristics of manufacturing enterprise and inventory management, the relationship between factors affecting inventory management is analyzed, and the causal relationship of $\mathrm{w}$ inventory management system is established, the dynamic model of $\mathrm{w}$ branch office inventory management system is established, the initial value of each variable and a series of system dynamics equations are established.

\author{
基于系统动力学的库存问题研究 \\ 刘威 $1, a,{ }^{*}$, 吕紫娴2,b \\ 1厦门大学嘉庚学院, 漳州, 中国 \\ 2 厦门大学嘉庚学院, 漳州, 中国 \\ aliuwei568@xujc.com, bSCL13048@stu.xujc.com \\ “通讯作者
}

关键词:制造型企业; 库存管理; 系统动力学; 仿真模拟

中文摘要.在分析制造型企业特点及库存管理的基础上, 利用库存管理和系统动力学理论, 在 结合W福州分公司的生产实际的前提下, 分析了影响企业库存管理的各个因素之间的关系, 并 利用系统动力学理论建立起企业库存管理中各因素的因果关系图, 构建了W福州分公司库存管 理系统动力学模型, 利用系统动力学VENSIM仿真软件, 将各个因素有机地联系起来, 确定了各 个变量的初值并建立了一系列系统动力学方, 程通过对W福州分公司库存管理系统动力学模型 的仿真测试和对仿真结果的分析, 表明了模型的稳定性和有效性。最后, 运用W福州分公司的实 际数据验证了模型的准确性和合理性, 进而证明了模型的实用性。

\section{1. 引言}

库存是指货物或货物存储条件。库存从物流管理的角度, 强调了合理化和效率, 以集成的 需求, 使企业活动顺利进行。

由于库存商品要占用资金, 发生库存费用, 而且可能有库存积压, 造成损失, 所以库存不 仅要防止脱销, 保持经营的连续性, 还要防止多余的库存, 避免不必要的库存成本。所以库存计 划和控制的关键是企业研究、库存管理理论应运而生。

系统动力学是福瑞斯特教授为分析生产管理及库存管理等企业问题而提出的系统仿真方 法, 最初叫做工业动态学。福瑞斯特发表的《工业动力学》成为经典著作。随后, 系统动力学 应用范围日益扩大, 几乎遍及各个领域, 逐渐形成了比较成熟的新学科一系统动力学。系统动 
力学是一门分析研究信息反馈系统的学科, 也是一门认识系统问题和解决系统问题的交叉综 合学科。系统动力学是综合结构的方法、功能的方法和历史的方法的一门学科, 是结合自然科 学和社会科学的横向学科。

系统动力学的基本思想是充分认识系统中的反馈与延迟, 主要任务是确定系统中的因果 反馈、时间延迟的逻辑结构, 进而按照一定的规则建立系统的因果关系图, 并完成系统动力学 流图、写出变量方程, 最终运用计算机模拟出模型的数值解。

\section{W福州分公司库存管理系统动力学模型的构建}

\subsection{W福州分公司简介}

$\mathrm{W}$ 公司成立于 2003 年 1 月 8 日，位于青岛市，一期投资总额 2 亿人民币，由A集团与W共同 投资在青岛建立的商用空调技术开发、产品制造、市场销售和用户服务为一体的大型合资企 业。 $\mathrm{W}$ 目前主打产品为 $\mathrm{S}$ 变频多联式商用空调系统和 $\mathrm{F}$ 变频家用中央空调系统, 二者均采用 $\mathrm{W}$ 最先进的核心技术，从青岛行销海外多个国家。

\subsection{W福州分公司存在问题分析}

W 福州分公司采用订单式生产方式, 根据市场订单安排生产计划, 进而进行原材料与外协 零部件的采购及库存管理工作, 订单式生产方式既可以提升客的满意度, 又可以提高企业的生 产效率, 同时可以保持库存在一个合理的水平上, 因此, 企业受市场影响的风险较小。在库存 管理方面, 公司仍然采用传统的 $\mathrm{ABC}$ 分类方法来管理原材料、外协零部件库存, 并且都设有安 全库存。公司实行材料定点采购, 不经过中间商, 既保证了低成本, 又保证了材料规格的准确 性, 原材料、零部件供应网络比较健全。而对于半成品库存及产成品库存的管理, 公司则通过 市场订单及市场需求预测来控制库存并制定相应的生产计划, 公司持有一定数量的安全库 存。但通过实地资料分析和现场调研，发现W 福州分公司在库存管理方面存在如下问题。

(1) 库存总量大, 周转时间长, 占用大量流动资金。W 福州分公司主要根据经验对库存进 行管理, 为满足市场及生产需求, 企业会设置较高的库存量, 库存量过多, 不仅占用大量流动 资金, 而且新商品的出现必将使其价值缩水, 加大库存风险。

（2）库存结构不合理。库存结构合理化指的是企业在生产经营活动中应保持原材料在制 品、产成品的适当比例, 而不是只考虑某种因素, 只有当各个阶段的库存量相互协调时才能保 证生产的顺利进行。因此, 库存管理要综合考虑公司内部的各个因素, 使整个企业协调起来。

(3) 合作性差。公司各部门以自己的利益为出发点来管理库存, 而不是从全局利益着眼, 这就造成了整个企业不能达到效益最优化和利益最大化, 因此, 为了提高整个公司的整体效益, 需要增加各部门之间的合作性。

（4）库存管理不能动态反映实时库存和消耗。企业产品出入库频繁, 库存管理部门每天 要处理的收发单据数量较大, 管理人员不能准确地知道仓库的库存量变化, 并且不能及时掌握 生产变动及车间用料情况。

\subsection{W福州分公司库存管理相关因素分析}

W福州分公司产品种类繁多, 工艺复杂, 本论文以H型号空调为例进行库存管理研究, 在研 究过程中, 企业生产的各个阶段都只选定一种产品来进行研究。根据W公司现有规模, 在考虑劳 动力因素和生产能力的情况下, W公司每月最多可生产3500台H型号空调。

根据公司长时间的生产管理经验及统计的历史库存数据, 当原材料库存为 300 件, 半成品 库存为 300 件, 成品库存在 250 件时, 公司运转稳定且满足客户要求, 处于良好的发展状态。 目前W公司每月订单为 3000 件左右, 公司负责生产H型号空调的工人有 70 左右, 40 人负责加工原 材料, 大约每人每月加工 60 件左右, 其余 30 人负责组装半成品, 大约每人每月组装 80 件左右。 
与原材料库存相关的影响因素主要包括原材料采购率、原材料入库率、原材料出库率、 原材料采购延迟时间、原材料期望库存和原材料采购调整时间。原材料采购率指的是每月采 购原材料的量。原材料入库率指的是每月原材料进入库存的量。原材料发货率指的是每月原 材料的出货量。延迟是指数量的变化需要经过一段时间的滞后才能得到响应, 原材料采购延迟 时间指的是原材料采购过程中需要一定的时间滞后才能完成原材料采购。而 $\mathrm{H}$ 型号空调原材料 主要由两大类组成。A类为普通零部件原材料, 该类材料在本省或邻省即可采购完成; B类则 是进口零部件或是总公司生产的专利零部件原材料, 该类原材料采购时间较长。根据W公司长 时间的统计数据, A类原材料采购延迟大约在 2 天； B 类原材料采购延迟大约是 6 天。原材料期望 库存指企业期望的最合理的原材料库存数量, $\mathrm{A}$ 类原材料安全库存大约为 300 件; 原材料库存调 整时间指的是弥补原材料库存缺货所需要的时间, 这个值越低则表明弥补速度越快, 根据经验, 库存调整时间并不是越快越好, 那样容易发生调节过量, 导致库存量反复振荡, 但如果时间过 长, 则调节速度缓慢, 可能导致库存缺货持续恶化现象, 原材料库存调整时间大约为 2.5 天。

与半成品库存相关的影响因素主要包括半成品产量、产成品产量、半成品劳动生产率、 劳动力调整时间、完成半成品劳动力。W公司半成品劳动生产率为每人每月 60 件左右, 半成品 期望库存为 300 件左右, 劳动力调整时间 3 天。企业中新招聘的劳动力需要经过一定时间的培 训才能上岗工作, 因此企业培训新职工所需要的时间就是劳动力调整时间, $W$ 公司劳动力调整 时间为 3 天左右。

与成品库存相关的影响因素主要包括生产延迟、销售率、成品产量、成品期望生产能力、 成品劳动生产率、成品库存调节率、完成产成品劳动力、产成品库存调节时间、成品期望库 存和需要达到的产成品产量。生产延迟是指生产需要一定的时间滞后才能完成, W公司生产延 迟大约为 2 天, 成品劳动生产率为每人每月 80 件左右, 成品库存调整时间大约为 2.5 天, 成品安 全库存量为 250 件左右, 需要达到的产成品产量由销售率和成品库存调节率决定, 但由于企业 的生产能力取决于劳动力因素和企业设备的生产能力, 劳动力的供应不可能是无限制的, 企业 设备的生产能力也是有限的, 所以, 需要达到的产成品产量不能超过企业的最大生产能力, 即 每月3500件。

\subsection{W福州分公司库存管理因果关系图}

在对该公司生产模式及库存管理各影响因素调查与分析的基础上, 根据系统动力学的理 论与方法, 建立该公司库存管理系统因果关系图, 模型具体的条件假设如下:

1. 制造企业采取订单驱动式的生产模式，即企业生产、原材料采购以销售订单来驱动的 “拉动式策略” ;

2. 模型中仅考虑某代表性产成品及与之匹配的一种中间产品、原材料;

3. 产成品为独立需求产品，产成品及中间产品对原材料的相关需求系数相同;

4. 企业内部各节点职能部门无信息延迟，仅考虑生产物质延迟;

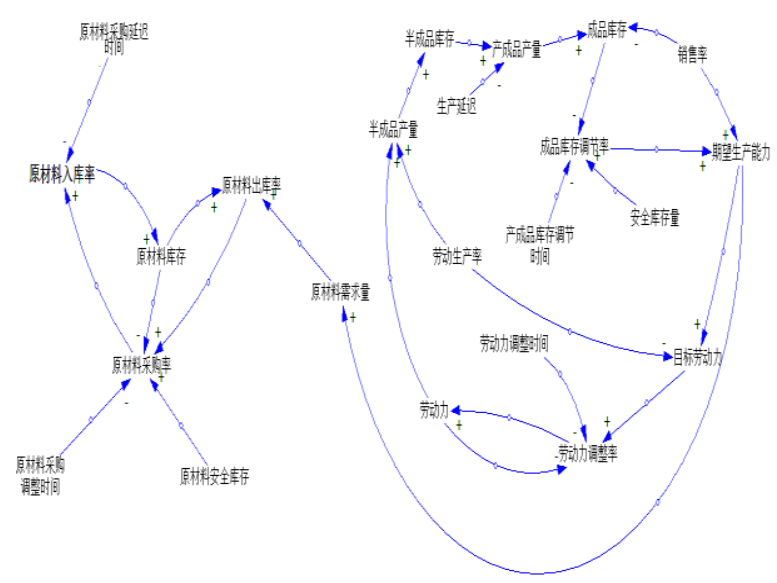

图1 W福州分公司库存管理因果关系图

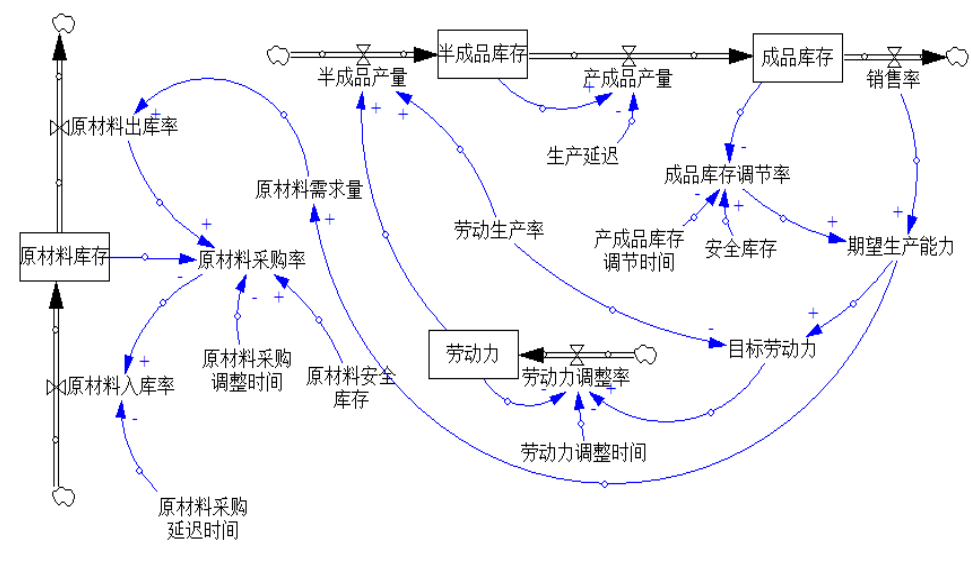

图2 W福州分公司库存管理系统动力学流图 


\section{$2.5 \mathrm{~W}$ 福州分公司库存管理系统动力学模型}

系统动力学中, 通常把变量分为流位变量、流率变量、常量和辅助变量。流位变量指的是 具有积累效应的变量, 所谓具有积累效应的变量就是指现时值等于原有值加上该变量, 而且存 在量的变化速度的这种变量。流率变量又称为速率变量和决策变量, 当物流和信息流停止时, 流率的值为零。在计算过程中不随时间变化的量称为常量。从信源到流率变量之间的中间变 量称为辅助变量。

根据以上系统动力学中规定的变量种类, 在分析模型中各个变量的基础上, 进而确定模型 中各个变量的类型。模型中的常量包括原材料采购延迟、原材料采购调整时间、原材料安全 库存、生产延迟、产成品库存调节时间、产成品安全库存、劳动力调整时间、目标劳动力。 流位变量包括原材料库存、半成品库存、成品库存、完成半成品劳动力。流率变量包括原材 料入库率、原材料发货率、半成品产量、产成品产量、销售速率。辅助变量包括原材料采购 率、成品库存调节率。库存管理系统动力学流图, 如上图2所示。

\section{3. 库存管理系统动力学模型仿真结果分析}

\section{1 模型中各参数的确定}

库存管理系统动力学模型建好以后, 就要对模型中各个变量的初始值及计算方程进行输 入, 进而把模型中各个变量之间的关系由定性分析转换到定量分析上来。 ${ }^{[6]}$ 系统动力学模型内 部是按照时间序列顺序进行计算的, 在建立系统动力学模型时, 首先对模型中模拟仿真的初始 时间、结束时间、时间模拟步长及时间单位进行确定。

W福州分公司库存管理系统动力学模型中的变量方程及初始值如下所示。

(1) INITIAL TIME $=0$, 单位: 月

(2) TIME STEP $=1$, 单位: 月

(3) SAVEPER=TIME STEP, 单位: 月

(4) FINAL TIME $=100$, 单位: 月

（5）原材料采购延迟时间 $=0.07$, 单位: 月

（6）原材料库存调节时间 $=0.08$, 单位: 月

（7）原材料安全库存 $=300$, 单位: 件

（8）生产延迟时间 $=0.06$, 单位: 月

（9）劳动力调整时间 $=0.1$, 单位: 月

（10）成品库存调节时间 $=0.08$, 单位: 月

(11) 原材料需求量 $=$ 原材料需求系数 $\times$ 期望生产能力, 单位: 件 $/$ 天。最终产成品是独立 需求的产品，而原材料与成品之间存在相关需求关系，为相关需求物资。

(12) 原材料库存 = INTEG (原材料入库率一原材料出库率, 原材料初始库存量), 单位: 件。

(13) 原材料采购率 $=$ (期望原材料库存一原材料库存) / 原材料采购调整时间 + 原材料出库 率, 单位: 件/天。

（14）原材料入库率=Delay1 (原材料采购率，原材料采购延迟时间），单位：件/月。由于 存在运输延迟时间的存在, 企业当天收到的入库原材料是延迟时间之前向上游供应商所采购 的原材料，故采用一阶延迟方程 Delay1 (原材料采购率，采购延迟时间)表示。

（15）原材料出库率 $=\mathrm{SMOOTH}$ (原材料材料需求量, 原材料出库平滑时间), 单位: 件/月。

（16）产成品产量＝半成品库存/生产延迟, 单位: 台/天。产成品产量为流率变量, 它表 示在生产延迟时间内中间产品生产加工为成品的速率。

(17) 成品库存 $=$ INTEG (产成品产量一销售率, 成品库存初始量), 单位: 台。成品库存量 是一个流位变量, 它是产成品产量和市场销售率的积分。

(18) 成品库存调节率 $=$ (安全成品库存一成品库存 $) /$ 成品库存调节时间, 单位: 台/月。 
（19）半成品产量 $=$ 劳动生产率 $\times$ 劳动力，单位：台/月。

(20) 半成品库存 $=\operatorname{INTEG}$ (半成品产量一产成品产量, 半成品库存初始量 $=300$ ), 单位: 台。

(21) 劳动生产率 $1=50$ 单位: 件/月/人

(22) 销售率 $=0.65$ 。

（23）期望生产能力＝成品库存调节率十销售率，单位：台/月。

(24) 目标劳动力 $=$ 期望生产能力/劳动力生产率, 单位: 人。

（25） 劳动力调整率 $=($ 目标劳动力一劳动力 $) /$ 劳动力调整时间, 单位: 人/月。

(26) 劳动力 $=I N T E G$ (劳动力调整率, 期初劳动力数量), 单位: 人。

\section{2 模型仿真结果分析}

论文根据W福州分公司的生产实际和长时间的统计数据确定了模型中部分变量的值和初 始值, 建立了一个符合W福州分公司实际的库存管理系统动力学模型。在企业生产经营过程中, 当一些变量、生产情况及销售情况发生变动时, 必须根据企业实际对模型中的参数进行调整。 下面对模型进行仿真及仿真结果分析。根据实际状态下仿真结果如图3和图4所示:

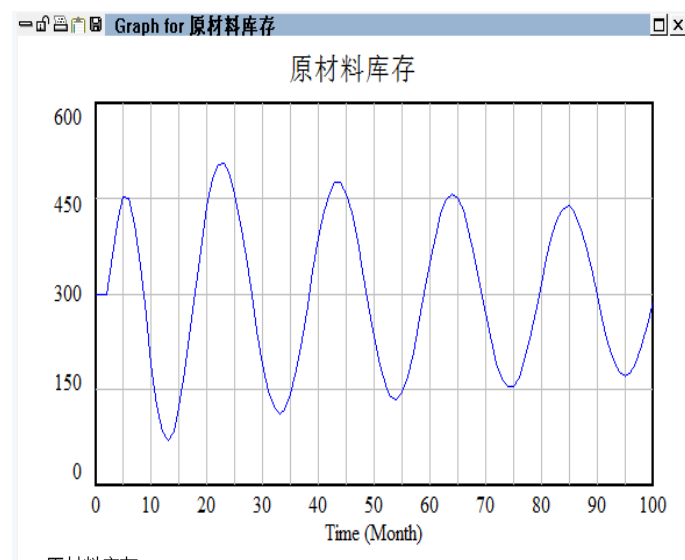

原材料库存: current 0 图 3 原材料库存仿真结果

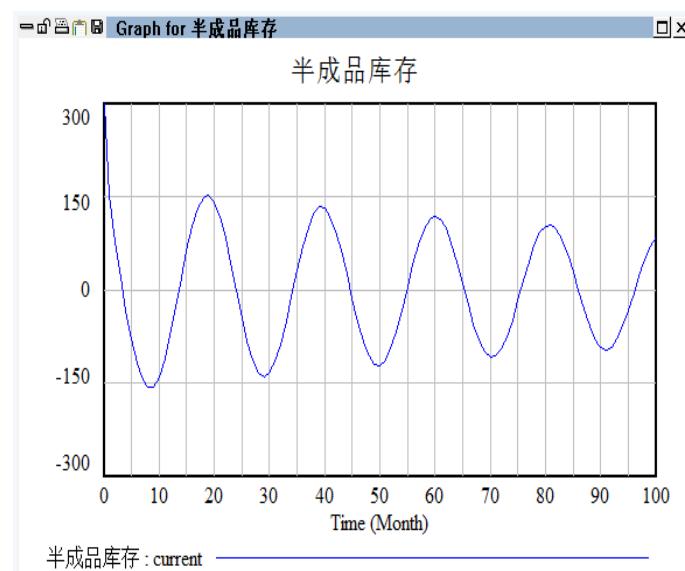

图4 半成品库存仿真结果

从原材料库存仿真结果图3中可以分析出, 在市场需求不断变动的情况下, 原材料库存波 动也较为剧烈。在模型仿真时间内和市场需求情况下, $W$ 福州分公司原材料库存最大值为500 件, 随着时间的变化波动趋势逐渐减弱。

从半成品库存仿真结果图 4 中可以分析出, 在模型仿真时间内和市场需求情况下, W福州分 公司半成品库存最大值为 300 件, 最大库存缺货 153 件。随着时间的延长, 半成品库存的最大库 存量和缺货量的趋势都逐渐减弱。

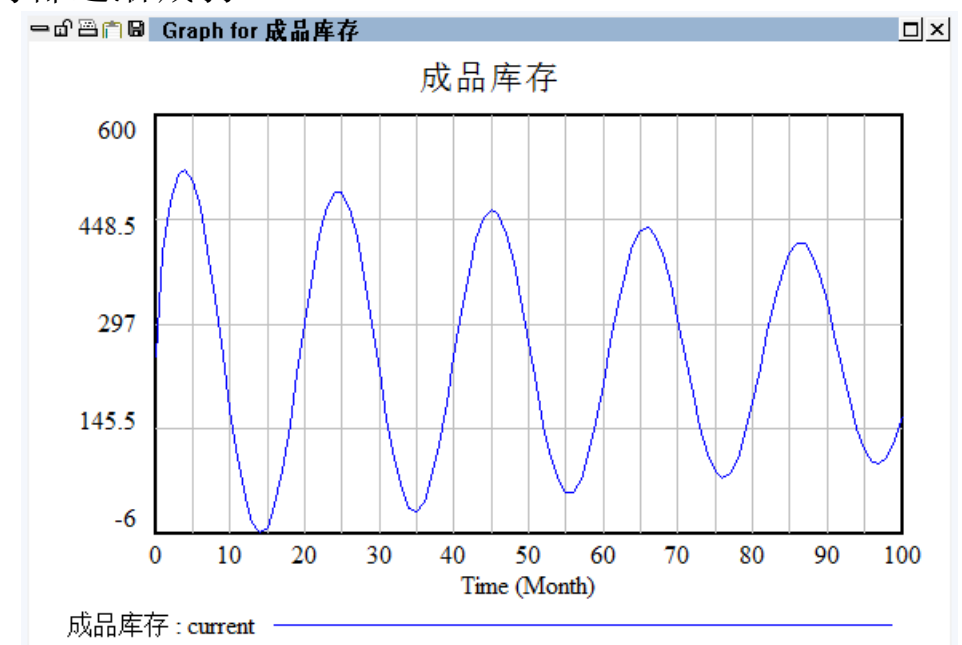

图5 成品库存仿真结果 
从成品库存仿真结果图5中可以分析出, 在市场需求不断变动的情况下, 成品库存波动也 较为剧烈。在模型仿真时间内和市场需求情况下, $W$ 福州分公司成品库存最大值为540件, 且库 存量都较大, 缺货情况不显著, 为6件。同样, 随着时间的延长, 成品库存的库存量波动趋势 逐渐减弱。

根据现收集的资料以及数据分析，模拟出了W福州分公司的原材料库存、半成品库存和成 品库存在未来100个月中的走势图。接下来可通过灵敏度分析, 试图优化该公司的原材料、半 成品和成品库存，相对稳定其生产，为公司节省成本。

在对库存管理系统动力学模型进行变量确定及方程输入的基础上, 利用VENSIM软件对W福 州分公司库存管理系统动力学模型进行仿真分析, 若是最简单最理想化的模型, 即假设W福州 分公司不存在原材料采购延迟、调整时间和生产延迟现象, 并且客户的需求保持在稳定的每月 3500 件。但是, 运用在实际中是不现实的, 为方便模型运行, 将模型中的时间作为实验变量, 生产能力和劳动力等因素保持原有数据。在一个合理的范围内, 经过多次灵敏度分析实验, 多 次运行模型，找出实际中最优的时间对公司最有益的结果图。最终得出，当原材料采购时间 缩短为 0.5 天时; 原材料采购调整时间缩短为 0.5 天; 生产延迟时间缩短为 1 天; 成品库存调整 时间缩短为 1 天和劳动力调整时间缩短为 1.5 天。优化时间后, 库存系统管理仿真结果如下图 6 和图7所示:

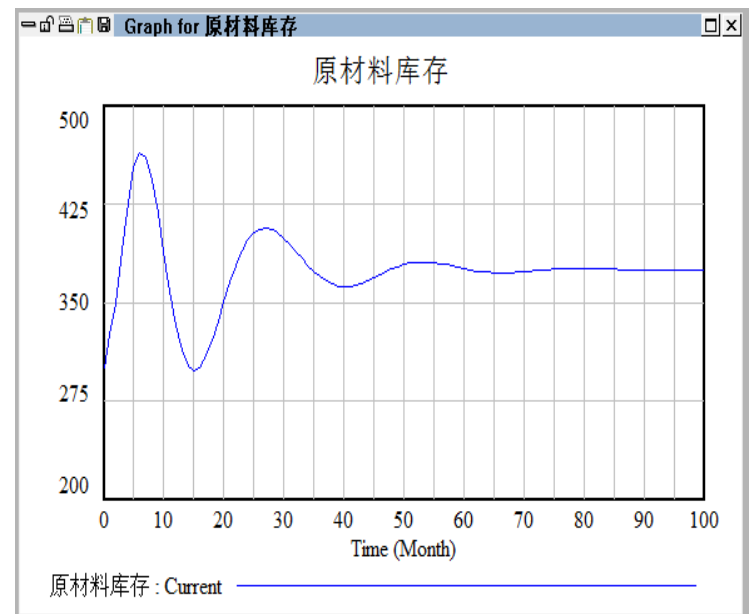

图6 调整后原材料库存仿真结果

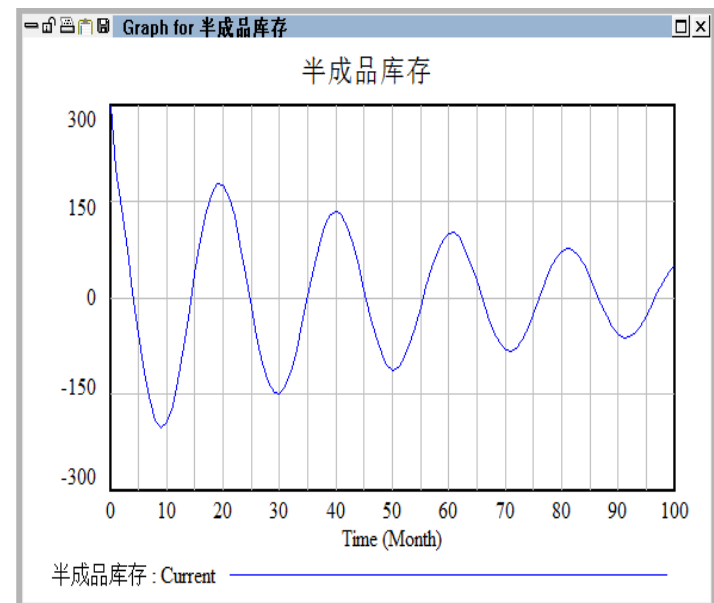

图7 调整后半成品库存仿真结果

原材料库存设定为 300 件, 前期波动较为明显, 因为有起初的原材料入库作用在影响原材 料库存, 在 50 个月以后, 模型趋近平稳状态。原材料库存稳定在 370 件左右。

如图7所示, 前 20 个月半成品库存波动较为剧烈, 之后趋于平缓。原材料采购时间缩短和 劳动力调整时间缩短后, 半成品库存的周转有效提升, 库存积压得到改善。

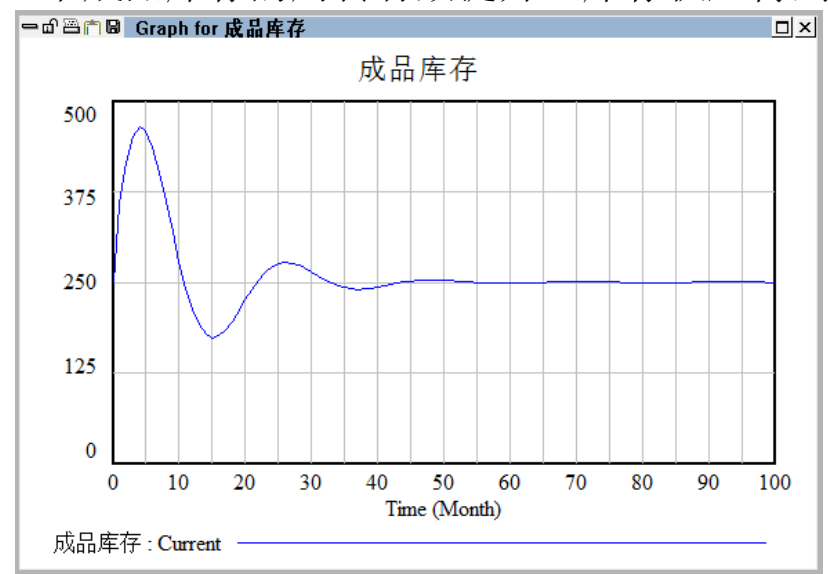

图8 调整后成品库存仿真结果 
如图8所示, 前十个月成品库存迅速增加, 是由于模型时间突然缩短, 半成品库存减少, 加工成产成品, 所以成品数量增多。之后整个模型共同运作, 趋势得到稳定。在 30 个月后, 模型数值接近于安全库存并长时间维持在 250 件。

综上所述，将模型的时间上经过多次灵敏度分析，得出结论：当原材料采购时间缩短为 0.5 天时; 原材料采购调整时间缩短为 0.5 天; 生产延迟时间缩短为 1 天; 成品库存调整时间缩 短为 1 天和劳动力调整时间缩短为 1.5 天; 能降低公司库存管理成本, 并且公司能快速的预测 接下去的生产情况, 同时, 公司原材料库存应由现有的300件增加至370件; 公司成品的安全 库存应为 250 件, 这样公司运转稳定, 能够满足市场随机的需求变动。

\section{3 模型结果优化方案}

根据上文实际情况可知，原材料分为 $\mathrm{A} 、 \mathrm{~B}$ 两大类。而 $\mathrm{B}$ 类的进口零部件原材料采购在不同 地区, 若想要实现模拟出的结果 0.5 天采购时间, 有一定难度。又因为B类原材料采购时涉及 到供应商、经销商和零售商三方, 为达到该结果, 建议针对 $\mathrm{B}$ 类原材料的库存管理引进一项新 的库存管理策略一一供应商管理库存（VMI）。针对供应商不在用户的所在地, 但是定期派人 代表用户执行存货决策, 管理存货, 供应商拥有库存的所有权。供应商拥有所有权的情况下, 采取在用户地或是在分销中心保存库存, 以求根据需要及时快速的补充, 库存的水平由供应商 决定。为实现 0.5 天的采购时间, 作者建议可在W福州分公司附近设立仓库存放B类货物; 或W 福州分公司直接在组装厂周边设立仓库, 专门存放B类原材料。这样可以缩短采购时间, 同时 又可以降低采购频繁所导致的各类成本。

供应商管理库存（VMI），是指由上游企业来管理其下游合作伙伴的库存，特指供应商与 零售商共享数据, 供应商根据零售商的库存水平以及销售记录, 再依据预先制定的库存策略 对零售商库存进行连续补货的一种贸易伙伴间的合作策略。供应商管理库存是为了解决传统 的库存管理模式, 各自为政, 信息多重处理, 各个节点企业都设置安全库存, 这就不可避免 可能导致信息失真, 安全库存重复也使得供应链上库存过高。在快速响应市场环境下供应商 管理库存应时而生, 供应商管理库存的思想打破了传统的各自独立的库存管理模式, 体现了 供应链集成化管理思想。供应商和零售商之间的紧密合作，改善了整个系统的流程，实现了 信息的高度共享。 ${ }^{[7]}$

为实现前一节模型模拟出的结果, 并结合VMI模式, 做出了改进后的B类的W福州分公司原 材料管理的VMI因果图, 如图9所示:

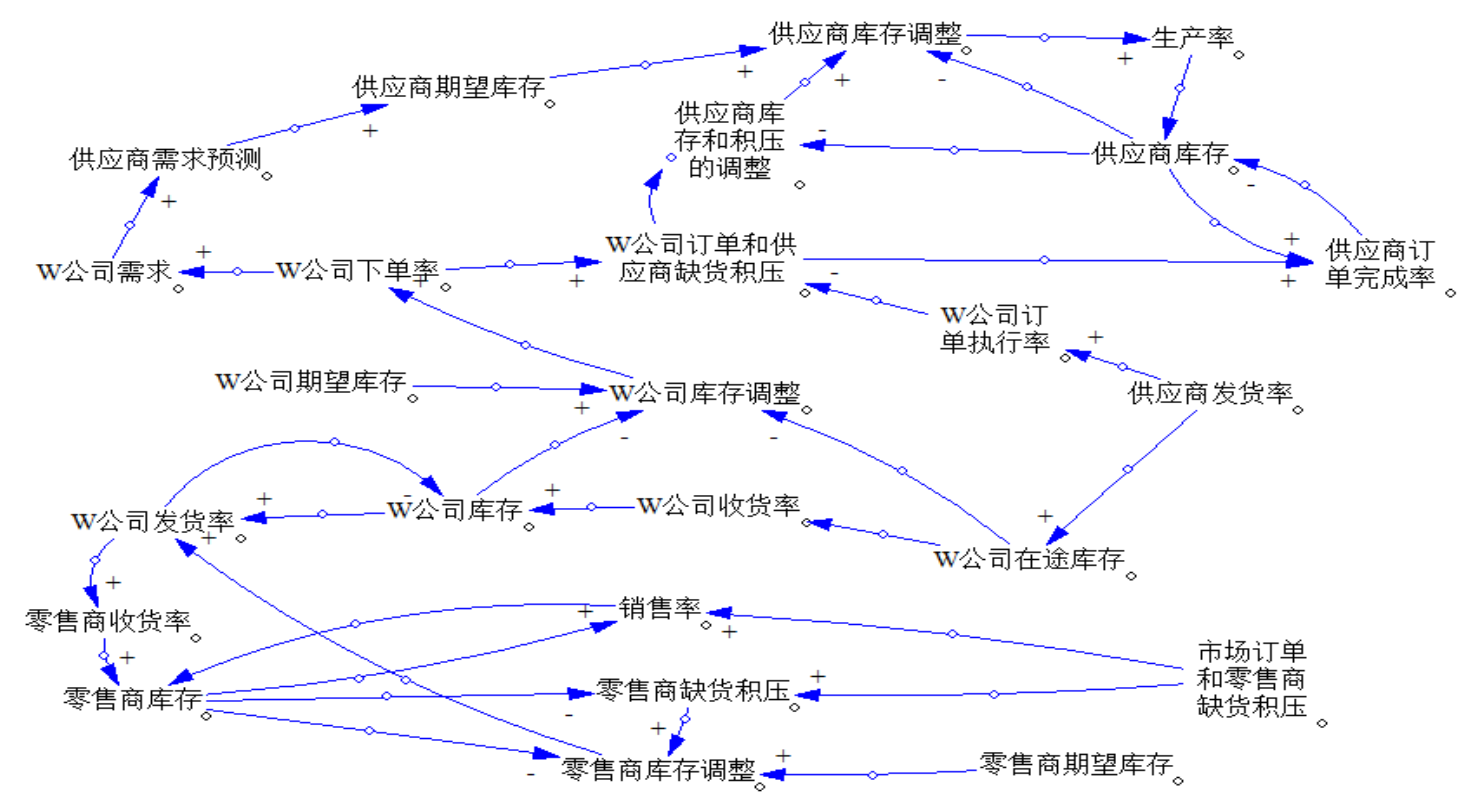

图9 B类原材料管理VMI因果图 
供应链库存管理模式下零售商库存管理的管理主体是供应链的最上游的制造商，即图中 供应链中的供应商。由图可知供应链中零售商根据市场需求进行销售预测, 然后将销售预测 信息传递给上游企业。VMI模式下零售商的订货量是由供应商制定的, 供应商根据制定的订货 量向下游补货。零售商库存得到补充, 零售商库存差为零, 零售商库存和零售商期望库存相 等。整个物流循环过程，零售商通过EDI等信息技术，将市场的需求信息传递给上游企业，供 应商根据得到的信息制定补货计划, 向下游补货, 使得零售商模块实现平衡。供应商依据零 售商销售预测制定出供应商期望库存量, 控制供应商的生产, 随着生产的完成, 供应商库存 增加，供应商向下游W公司发货，使得供应商库存减少，循环下去使得供应商库存维持平衡。 W公司库存不仅要完成对零售商库存的准时补货, 其变动也是供应商制定生产计划的重要依 据。供应商根据W公司库存和W公司订单制定计划, 并将补货信息传递给供应商, 调节供应商 发货率，对W公司库存进行补货，W公司库存模块在供应商发货率和W公司发货率的作用下达到 平衡。

$\mathrm{B}$ 类原材料采购系统动力流图如下图10所示:

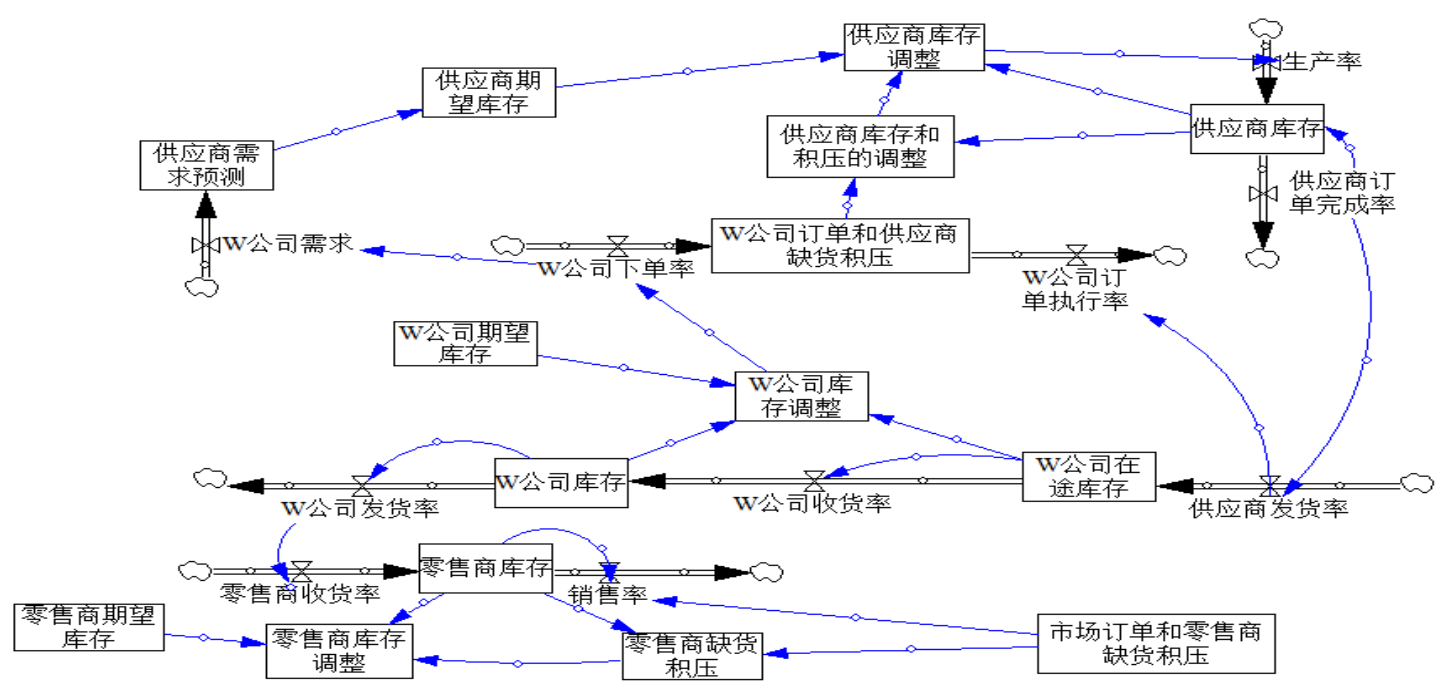

图10 B类原材料库存VMI流图

根据多次调研数据可得，W福州分公司B类原材料的采购时间为6天，原材料库存调整时间 为 4 天。B类原材料库存 200 件, 原材料库存调整 80 件, 原材料在途库存 50 件, 原材料期望库存 50 件。供应商库存 500 件, 供应商期望库存 300 件, 供应商库存调整 100 件, 供应商库存积压调 整 100 件, 供应商需求预测 200 件, 零售商库存 80 件, 零售商库存调整 30 件, 零售商期望库存 20 件，零售商缺货积压 20 件，市场订单和零售商缺货积压 20 件。

将该模型代入调研数据，模拟出W公司B类原材料库存最终结果图如下:

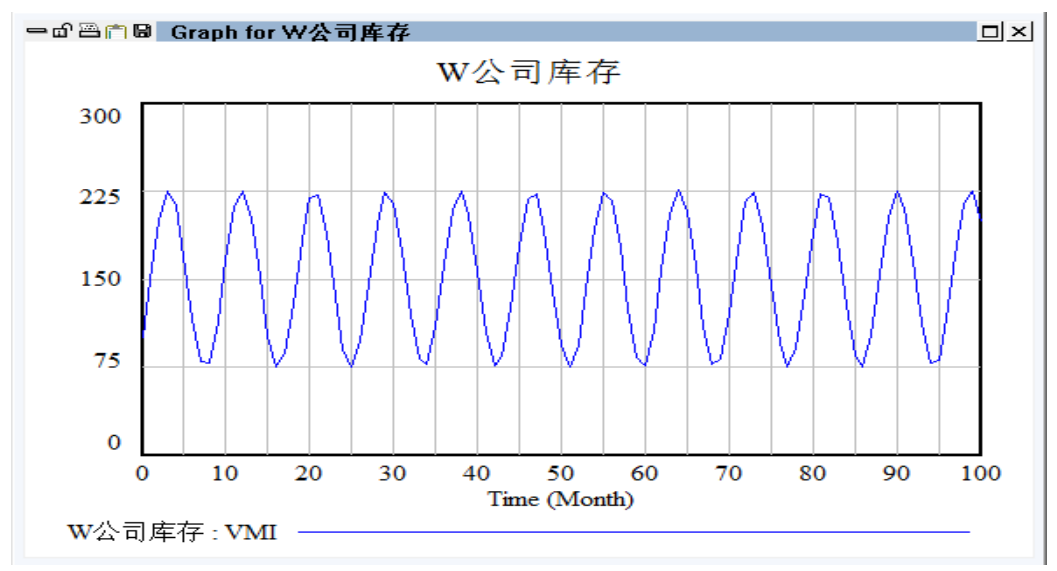

图11 W公司B类原材料库存 
综上所述，W福州分公司B类原材料采用VMI系统动力学模拟结果如上图所示，波动结果呈 现较稳定状态, B类原材料库存波动范围在 75 至 225 件内, 平均 150 件, 适当根据销售情况进行 调整是可以满足 $W$ 福州分公司的生产需求，且能满足 $H$ 型空调的原材料采购时间为 0.5 天。

\section{4. 结论}

论文运用系统动力学理论方法, 并结合W福州分公司空调企业的库存控制实际情况, 对W 福州分公司的库存控制系统进行研究, 在结合W福州分公司的生产实际的前提下, 分析了影响 企业库存管理的各个因素之间的关系, 并利用系统动力学理论建立起企业库存管理中各因素 的因果关系图, 在因果关系图的基础上, 构建了W福州分公司库存管理系统动力学模型, 利用系 统动力学仿真软件, 将各个因素有机地联系起来, 确定了各个变量的初值并建立了一系列系统 动力学方程通过对W福州分公司库存管理系统动力学模型的仿真测试和对仿真结果的分析, 优 化了W福州分公司在原材料采购时间上的影响因素以及库存管理方法, 找出了最短的时间。而 且, 在原材料的管理上进行分类, 并且为其可行性想出了解决方案, 降低了库存量, 为公司 降低了成本，并能稳定发展。

最终得出的可行性结果是，原材料采购时间缩短为 0.5 天时；原材料采购调整时间缩短为 0.5 天; 生产延迟时间缩短为 1 天; 成品库存调整时间缩短为 1 天和劳动力调整时间缩短为 1.5 天。而为实现这短时间的采购, 在原材料管理上, $\mathrm{A}$ 类原材料可按照传统模式进行管理, 库存 量为370件较为合理。而B类远距离采购的原材料设立一个分仓库专门存储, 管理方式采用VMI 模式, 库存量为 150 件, 因为仓库距离近, 能满足H型空调的原材料采购时间为 0.5 天这一条件。

库存管理的现实意义建立了库存控制系统 SD 模型, 运用 VENSIM软件进行了仿真模拟及 结果分析。由仿真结果可知该 SD 模型能较好地反映实际系统, 企业管理者可通过尝试各种 不同的现实模拟策略, 来寻求控制库存波动的优化参数、系统结构及有效策略, 为生产企业 管理者的决策提供了实验空间及可靠依据。

\section{References}

[1] Wang binyi. Modern logistics practice. Beijing:university of International Business and Economics press, 2003.

[2] Sun minggui.Inventory and Logistics Management.Beijing: China Social Sciences Press,2005.

[3] Forrester J W.Industrial dynamics.Cambridge Mass:MIT Press,1961:36.

[4] Sterman J D. Modeling managerial behavior: Misperceptions of feedback in a dynamic decision making experiment.Management Science, 35(3),pp.321-339,1989.

[5] Jia huiwen.Study on the system dynamics model of inventory management in Hong Yu corporation. Shandong University of Science and Technology,2010.

[6] Liu zhiyan, Li nailiang, Han keqi. Research on inventory management. China Water Transport, Volume 11, pp.240-242, 2007.

[7] Zhou sanyuan. Logistics system dynamic. China fortune press.2014. 